\title{
O sentido da fumaça: a circulação da obra de arte e da imagem em y Lucientes de Nuno Ramos ${ }^{1}$
}

\author{
Érica Boccardo Burini²
}

Resumo: O artigo trata da circulação de imagens dos Desastres da Guerra de Goya, que aparecem em y Lucientes de Nuno Ramos; e da circulação da série de Ramos, que foi apresentada na Art Basel em Miami, e posteriormente, um fragmento dessa série, foi exibido na Galeria Reocupa, na Ocupação 9 de Julho em São Paulo.

Palavras-chave: Nuno Ramos, Francisco Goya, biografia cultural das coisas, circulação de obra de arte

\section{The sense of the smoke: artwork and image circulation in y Lucientes, by Nuno Ramos}

Abstract: This article deals with the circulation of images from the The Disasters of War by Goya, which appear in y Lucientes by Nuno Ramos, and the circulation of Ramos' series, which was presented in Art Basel Miami Beach, and later, a fragment of that series, was displayed at Galeria Reocupa, at Ocupação 9 de Julho in São Paulo.

Keywords: Nuno Ramos, Francisco Goys, cultural biography of things, artwork circulation

$1 \mathrm{O}$ artigo é fruto da pesquisa de Mestrado em História da Arte no IFCH-Unicamp, que recebeu fomento da Capes e atualmente é fomentada pela FAPESP, número de processo 2019/17706-0.

2 Mestranda em História da Arte no IFCH-Unicamp, sua pesquisa teve fomento da CAPES e tem da FAPESP (2019/17706-0). Graduada em Artes Visuais no IA-Unicamp em 2017. Colaborou com o Gabinete de Estampas - Departamento de Gravuras e Desenhos da Unicamp. Sua pesquisa tem ênfase em História da Arte, atuando principalmente nos seguintes temas: Francisco Goya, Marcello Grassmann, gravura, biografia cultural das coisas, processos de criação e coleção. Universidade Estadual de Campinas (IFCH/Unicamp). E-mail: erica.burini@gmail. com. ORCID: https://orcid.org/0000-0003-1318-645X. Lattes iD: http://lattes.cnpq.br/8457978100489462. Campinas, Brasil 


\title{
Arte brasileira nacional, internacional ou decolonial: questões de identi- dade nacional e decolonialidade
}

A questão da identidade nacional e a relação entre a produção artística local e global, renovadas ao sabor único de cada momento histórico, parecem sempre rondar a história da arte brasileira ${ }^{1}$. Tadeu Chiarelli resgata essas questões no texto Da arte nacional brasileira para a arte brasileira internacional, que integraria o catálogo da exposição Arte/Art: Latin American Work on Paper, com curadoria de Charles Merewether, na Biblioteca Pública de Nova York, que teria ocorrido no início de 1994, se não tivesse sido cancelada. Chiarelli (2002: 39) narra a história da arte brasileira recente desde meados do século XIX até fins do século $\mathrm{XX}$, quando o texto foi elaborado, sob o ponto de vista das perturbações causadas pelo problema da arte nacional versus arte internacional.

\begin{abstract}
A partir dos anos 80 , porém, os artistas não apenas dialogam conscientemente com a arte brasileira do passado, mas reconhecem a legitimidade da mesma e a qualidade de muitos de seus produtores, sejam eles modernos, modernistas, barrocos, eruditos ou populares.
\end{abstract}

Tal reconhecimento representa na verdade um amadurecimento do circuito artístico brasileiro que pela primeira vez - e de maneira crítica, nunca ufanista - parece estar passando a pensar a arte internacional levando em conta a contribuição dos artistas locais que de fato concorreram para a ampliação e o aprofundamento de seus conceitos. Uma atitude salutar de busca de autonomia e de descolonização.

E aqui estaria a principal contribuição desta geração que, atenta à cena internacional e rompendo definitivamente com o desejo de criação de uma arte nacional brasileira, começa a fundar de uma vez por todas a arte brasileira internacional.

O uso da expressão "autonomia e descolonização" parece evocar mais o sentido atual da decolonialidade, de transcender historicamente o domínio da colonialidade, que configura a hierarquia territorial, racial, cultural e epistêmica entre dominadores e dominados no sistema-mundo capitalista, que o sentido de superação do colonialismo, associado às insurgências e independências políticas das colônias em relação a suas metrópoles no século XIX na América Latina, segundo as categorias atualizadas pela discussão

1 A bibliografia sobre a questão é vasta, desde reflexões mais recentes, em Barcinski (2015) e Roberto Schwarcz (1987), bem como nos remotos tempos de Gonzaga Duque, Monteiro Lobato, passando pelo Modernismo, em indagações de Oswald de Andrade, tal como é comentado por Tadeu Chiarelli (2002) e Jorge Coli (2013), citando apenas alguns dos principais exemplos. 
das teorias decoloniais (RESTREPO; ROJAS, 2010: 16). O debate em torno dessas questões muito se desenvolveu desde a escrita do texto de Chiarelli, revelando a latência da ânsia pela inclusão da arte, das ideias e das formas de vida brasileiras em um debate global da arte contemporânea.

Na geração a partir dos anos 80 descrita por Tadeu Chiarelli, que alcança êxito em criar uma arte brasileira internacional, encontra-se o artista Nuno Ramos. Formado em Filosofia na Universidade de São Paulo, tem como marco inicial de sua carreira nas Artes Plásticas a participação no ateliê Casa 7, atuando como pintor desde 1984. Atualmente, sua obra percorre diversas materialidades, sendo ele criador de pinturas, desenhos, esculturas, instalações, filmes, cenografias, composições musicais, ensaios e livros em prosa. Mesmo em uma imensa gama de atuações, a obra de Ramos possui potência e coerência em torno da questão da materialidade e de seus possíveis sentidos.

Uma característica marcante da obra de Nuno Ramos, nos vários meios em que se materializa, das palavras escritas em mármore, até as escritas em papel, das imagens estáticas do desenho, até as que ganham movimento, das instalações que recebem músicas, às composições que se transformam em canções, das obras sonoras, das esculturas e pinturas superlativas, é a realização de operações de referências, citações, dedicatórias, homenagens, e atravessamentos, que elegem figuras de diversos meios culturais a serem celebradas, eliminando qualquer hierarquia que possa haver entre elas ${ }^{2}$.

As relações estabelecidas com a decolonialidade são esforços de uma leitura recente, empenhada em comparar o mecanismo do pensamento decolonial aos gestos do artista. "El pensamiento decolonial tiene como razón de ser y objetivo la decolonialidad del poder (es decir, de la matriz colonial de poder)" (MIGNOLO, 2007: 30). Na prática ensaística e na produção artística, o gosto pela cultura popular brasileira manifesta o desejo de introdução em igualdade, de conhecimentos anteriormente excluídos do panteão da modernidade, no sistema da arte contemporânea.

2 Dentre os homenageados, encontramos principalmente figuras da música popular brasileira, das artes plásticas, da literatura e, em especial, os 111 mortos no massacre do Carandiru. Exemplos: Pele 1 (Homenagem a Carlos Paraná) (SARDENBERG, 2010: 38); Pele 2 (Para Frida) (Ibidem: 40); Luz Negra (ParaNelson1) e Duas Horas (ParaNelson1) (Ibidem: 264) 


\section{Goeldi e Goya: o sentido da fumaça}

Na apresentação do livro Ensaio Geral, Nuno Ramos (2007: 9) introduz o leitor a seu modo de funcionamento transdisciplinar com a ideia de conversa. "É o ato de conversar que está na base destes ensaios, com todo o sonho frágil de harmonia, de democracia profunda que há numa conversa". O artista, que neste caso também é autor, tem uma característica de extrema erudição, grande conhecimento das artes e das ciências humanas, o que confere à sua obra a característica da complexidade. A noção de conversa exposta trata do extravasamento de barreiras existentes entre as mais diversas áreas da cultura, tendo as artes plásticas uma seção própria no livro, tal como a literatura, a canção, o futebol e o esporte, e os comentários de cunho autobiográfico ${ }^{3}$. Muitos dos textos contêm homenagens em seus títulos como dedicatórias, assinalando outras formas de conversa. Dentre os artistas aos quais se dedicou mais detidamente no livro, encontramos uma diversidade de afinidades eletivas: Hélio Oiticica, Bruce Nauman, Matthew Barney, Amílcar de Castro, Paulo Monteiro, Philip Guston, Fábio Miguez, Mira Schendel, Paulo Pasta e Oswaldo Goeldi (RAMOS, 2007). Dentre os artistas citados, o interesse por Goeldi é patente. Os frutos desse fascínio são abundantes, tal como a exposição Para Goeldi 1, na Galeria AS Studio, em São Paulo, que ocorreu em 1996, sobre a qual Kátia Canton (1996: n.p.) realiza alguns apontamentos na seção llustrada do jornal Folha de São Paulo.

O interesse de Nuno Ramos por Goeldi é consistente. O artista já havia escrito textos e realizado curadorias prévias sobre ele. Uma das razões da referência é a identificação com sua própria obra. "Goeldi tem uma fluidez poética, passa do fúnebre para o eufórico com um universo de elementos característico. Ele tem uma lógica noturna e alucinada, povoada de urubus, peixes, lanterneiros. Eu também realizo essa passagem entre o metafísico e o banal." Outra questão importante é a geracional. Abre a possibilidade de um artista brasileiro usar outro brasileiro como referência de sua própria história.

A observação acerca da chamada "questão geracional" entre Nuno Ramos e Oswaldo Goeldi, reitera a ideia exposta anteriormente na citação de Tadeu Chiarelli (2002: 39), sobre a maturidade do circuito artístico brasileiro e a possibilidade de um artista contemporâneo olhar para o passado da história da arte brasileira para construir seu presente e futuro, reconhecendo e legitimando a produção nacional no cenário global.

3 O livro conta com as partes: A terra (Literatura, canção), À espera de um sol interno (Arte), Os suplicantes (Esporte, futebol), É isto um homem? (A coisa pública), De giro em giro (A parte maldita). 
Figura 1 Nuno Ramos. Fumaça para Goeldi, 1996-2010. Fumaça sobre xerox de gravura de Oswaldo Goeldi, $60 \times 42 \mathrm{~cm}$. Fonte: (SARDENBERG, 2010: 148)
A exposição continha duas séries de desenhos e quatro esculturas, um urubu impresso em areia e silicato, uma mala, uma cadeira e um cesto fundidos em bronze, com lâminas de vidro derretidas sobre eles, espelhando a fluidez da obra de Nuno Ramos e o livre trânsito sobre diversas matérias e técnicas, dentro de sua linguagem coesa. Dentre as séries de desenho, estava Fumaça para Goeldi (SARDENBERG, 2010: 148-151), em que o artista desenha com marcas de fumaça e fuligem sobre reproduções de gravuras de Goeldi, que parecem vir de livros, e não das próprias obras. Em alguns casos, é revelada a legenda com dados da gravura, no canto direito aparecem números indicativos de paginação, e uma linha fina se desenha horizontalmente no terço inferior, indicando, talvez, o limite da página (Fig. 1). Os elementos bibliográficos se transformam em elementos puramente visuais. Deste modo, o artista retoma o domínio sobre a composição e gera um certo distanciamento das obras que seleciona. $O$ enquadramento das gravuras é ligeiramente alterado no papel, com a colocação da imagem na porção superior, restando um vazio branco abaixo, que é tomado pelo violento fumo de diferentes maneiras, em cada uma das composições. Os desenhos da mesma matéria inefável, adquirem diferentes pesos nas imagens, desde composições de sutis neblinas a densas fumaças industriais, em manchas de distintos tamanhos, formas e opacidades. 
A produção artística de Oswaldo Goeldi, em conjunto com a sua própria figura, representa a dificuldade da definição da brasilidade no campo das artes plásticas. Nuno Ramos (apud CANTON, 1996: n.p.) menciona a relutância nacional com as emoções transmitidas pela obra de Goeldi, como o abandono e tristeza, e o coloca em contraponto com a arte social de Portinari, valorizando a densidade literária do primeiro. Embora tenha nascido e falecido no Rio de Janeiro, a vida de Goeldi é entremeada por longas estadias na Europa. O conflito com a brasilidade também é familiar a Nuno Ramos, que tampouco encarna o modelo de expectativa da arte brasileira, tal como é comentado por Moacir dos Anjos e Agnaldo Farias em entrevista a Felipe Scovino (SCOVINO; MARTINS, 2012: 9) sobre a curadoria da $29^{a}$ Bienal, em que figurava a obra Bandeira Branca, que gerou polêmica também por lidar com afetos incômodos.

Pouco mais de 20 anos depois de Fumaça para Goeldi, Ramos apresenta y Lucientes ${ }^{4}$, em 2017. A instalação conta com 80 reproduções das gravuras de Los Desastres de la Guerra, de Francisco José de Goya y Lucientes, ou simplesmente Francisco Goya, expostas à fumaça e a fuligem liberadas por uma solda de acetileno ${ }^{5}$. As imagens obtidas guardam entre si grandes semelhanças na forma como exibem as marcas dessa emanação no papel.

A atenção de Nuno Ramos com as palavras é manifesta no título da série, que oferece um duplo sentido: $y$ Lucientes remete tanto ao nome materno de Francisco Goya, quanto à palavra luzentes, evocando a materialidade inefável desta fumaça que tudo toca, acrescentando ainda mais uma camada de gravidade nas pungentes imagens representativas das mais cruéis violações dos direitos humanos, características dos conflitos armados que ocorreram na Guerra Peninsular, também chamada Guerra de Independência Espanhola, marcada pela resistência popular e civil espanhola frente à truculência do exército napoleônico.

4 Esse projeto denota o desenvolvimento de uma ideia que pairava anteriormente na obra do artista. Um ano antes era exposta Lucientes 1, na Galeria Celma Albuquerque, em Belo Horizonte, em 2016, apresentando 80 desenhos com correspondências com as gravuras dos Desastres, com os mesmos títulos escritos, acompanhados de uma encadernação com o título The Disasters of War mergulhada em vaselina sobre mármore.

5 Informações retiradas do anúncio feito pela Anita Schwartz Galeria de Arte (Rio de Janeiro) sobre a participação de Nuno Ramos na Art Basel de Miami em 2017. Disponível em: <https://www.anitaschwartz.com.br/art-basel-miami-beach/> Acesso em 20 jan. 2020. 
Embora não tenha sido publicada em vida, a série Os Desastres da Guerra de Francisco Goya rendeu numerosas homenagens, releituras e apropriações, pela eterna atualidade do tema e também pela curiosidade com o que se crê ser o pensamento genuíno do artista, por ser uma série não feita por encargo, mas por capricho. Além do esmero e da vontade própria, a palavra também se aplica no sentido promovido pela língua espanhola de "obra de arte em que o engenho ou a fantasia rompem com a observância das regras"6. As novas obras aparecem em variantes de sabor sardônico, mordaz, abjeto, satírico, sarcástico, no caso dos irmãos ingleses Jake e Dinos Chapman, que intervêm nas gravuras com suas máscaras, ou ao tom de tradução aos dias atuais, como Dora Longo Bahia, em suas pinturas monocromáticas que relembram dolorosos conflitos do século XX, Primeira e Segunda Guerras Mundiais, a Guerra Civil Espanhola, a Guerra do Vietnã, a Guerra do Afeganistão, entre outras. As obras de Nuno Ramos optam por caminhos diferentes desses mostrados, ainda que enfrentem a mesma árdua tarefa do diálogo com os Desastres do mestre espanhol.

Na reportagem de Nelson Gobbi (2017: n.p.), de título "Nuno Ramos enfrenta com cores os tempos cinzentos da política", é apresentada a exposição individual Grito e paisagem em 2017 na Anita Schwartz Galeria de Arte e a concomitante participação na Art Basel de Miami, com a instalação y Lucientes. O próprio artista comenta as motivações da criação de suas pinturas e revela seu posicionamento político, de confesso desgosto com o estado do país após o impeachment de 2016, em um entrelaçamento entre a forma que suas obras adquirem, suas escolhas artísticas, e o sentimento causado pelo momento histórico pelo qual o país passava, resultado do paradoxo entre certo otimismo motivado pelo pessimismo, como a verdade que não é libertadora, mencionada pelo artista.

- Os quadros têm cores que nunca usei, como o rosa, o laranja, é um pouco estranho para mim, acho que as telas vêm de uma euforia raivosa. Queria que fosse uma coisa para cima, uma forma de dizer "vamos deixar esse bando de gente pequena para trás". A resposta para essa defuntada (sic) é viver - propõe Nuno, para quem o país se tornou, desde o impeachment de Dilma Rousseff, "paranoico e verdadeiro ao mesmo tempo". - A impressão que dá, quando ouvimos frases e pronunciamentos de autoridades, é que ninguém mente mais, mas essa verdade não foi libertadora. Ela reflete as forças políticas mais absurdas que emergiram, é uma verdade claustrofóbica. Temos que superar este real, é para isso que a gente vive, trabalha, sonha.

6 Definição oferecida pelo Dicionário da Real Academia Espanhola. Disponível em: <https://dle.rae.es/?w=capricho> Acesso em 20 jan. 2020. 
Um atravessamento histórico e cultural acontece na comparação entre esses sentimentos. A descrença nas instituições político-administrativas e a busca de uma saída pela arte apresentadas pelo artista ecoam a crítica à modernidade de Goya, que nasce da frustração com o pensamento ilustrado e a razão - tal como concebida nos parâmetros do lluminismo - que não foram capazes de deter o horror da Guerra Peninsular. A instabilidade causada por esse conflito na metrópole propiciou as Guerras de Independência na América Espanhola, influenciando também a Independência do Brasil. O encadeamento dos fatos não pode ser ignorado, especialmente devido à possível relação estabelecida entre as populações anônimas sofredoras das guerras, embora os resultados dos confrontos deflagrados sejam muito distintos em cada uma das regiões geográficas. A crítica à modernidade feita pelo pensamento decolonial aponta para o lado obscuro da mesma, que é o colonialismo e a colonialidade, e seus desdobramentos violentos, como a atrocidade da escravidão, e a subordinação política e econômica. No entanto, a modernidade de modo geral e os conhecimentos produzidos por esse paradigma não são de todo descartados, como aponta a seguinte citação:

La crítica del paradigma europeo de la racionalidad/modernidad es indispensable. Más aún, urgente. Pero es dudoso que el camino consista en la negación simple de todas sus categorías; en la disolución de la realidad en el discurso; en la pura negación de la idea y de la perspectiva de totalidad en el conocimiento. Lejos de esto, es necesario desprenderse de las vinculaciones de la racionalidad-modernidad con la colonialidad, en primer término, y en definitiva con todo poder no constituido en la decisión libre de gentes libres. Es la instrumentalización de la razón por el poder coIonial, en primer lugar, lo que produjo paradigmas distorsionados de conocimiento y malogró las promesas liberadoras de la modernidad. La alternativa, en consecuencia, es clara: la destrucción de la colonialidad del poder mundial. (QUIJANO, 1992: 437 apud MIGNOLO, 2007: 28)

Portanto, é entendido que a utilização contextualizada da obra de Goya, com a ideia de identidade entre os povos vitimados pelos conflitos e a irracionalidade absoluta que representa uma guerra, não reproduz a colonialidade combatida pelo pensamento decolonial. A contribuição do artista espanhol para o desenvolvimento da linguagem artística, especialmente sob o viés das relações entre arte e política, abre caminhos para a reinvenção dessas imagens, carregadas de sentidos preexistentes e sedentas por novos contextos. O modo como Goya realiza suas obras contestadoras, motivadas pela conjuntura social, é comentado por Fayga Ostrower (1997: 27) em seu livro sobre o artista, afirmando a necessidade de aliar o engajamento político à linguagem artística no processo criativo. 
A arte implica o seguinte: ao mesmo tempo que o artista diga 'não', negando, derrubando, destruindo - o que em si, isoladamente, não significa um ato artístico - ele teria de ser capaz de dizer 'sim', construindo, reconstruindo, e sempre em termos artísticos, ou seja, nos termos concretos e específicos de sua própria linguagem de arte. Não é nunca uma questão de discursos ou de conceitos abstratos, mas é uma questão de criação artística. Tanto a negação quanto a afirmação teriam de ser transformadas em formas expressivas enriquecendo a linguagem de arte.

A ideia exposta acima também remete à fala de Nuno Ramos, ao relacionar o uso das cores ao modo de expressar uma vivacidade combativa. Não apenas as imagens criadas por Goya ressurgem, mas também o seu modo de pensar o engajamento político na arte. A apropriação das imagens dos Desastres da guerra, que Ramos realiza em y Lucientes, configura um gesto artístico igualmente poderoso de contestação através da linguagem da arte.

De certa forma, o ressurgimento dessas imagens também mobiliza a memória gráfica brasileira, que de tantas formas bebeu da obra de Goya até a contemporaneidade. A história da gravura no Brasil tem data relativamente recente, sendo oficialmente implantada com a chegada da corte portuguesa em 1808, que suspendeu a proibição da prática de qualquer atividade gráfica na então colônia, vigente desde o século XVI. O florescimento da gravura no Brasil é em grande parte associado ao Modernismo, e Maria Luisa Tavora (2013: 121) localiza a maior difusão, uma espécie de "surto de produção de gravura, nos anos 50-60, estimulado pelas atividades em ateliês coletivos, que promoviam sua apropriação expressiva nos termos colocados pela arte moderna." Teixeira Leite desenha um panorama em seu livro Gravura Brasileira Contemporânea (1966), marco editorial de valorização deste meio artístico, citando expoentes gravuristas atuantes neste momento, que, no quesito técnico, põe em posição de igualdade face aos estrangeiros: Marcello Grassmann, Fayga Ostrower, Lívio Abramo, Renina Katz, Oswaldo Goeldi, Lasar Segall, Axel Leskoschek e Poty Lazzarotto. Também expõe as problemáticas do período em polarizações, entre arte nacional e internacional; tradição e vanguarda; valores técnicos e expressão.

A influência de Goya nestas figuras foi da mais variada, Teixeira Leite cita o aspecto literário (1966, p. 15) e o fantástico sarcástico (1966, p.17) de Goeldi. Esses aspectos parecem criar um elo de ligação entre Francisco Goya, Oswaldo Goeldi e Nuno Ramos. O artista contemporâneo constrói uma linhagem estética trans-histórica através da fumaça, cuja intervenção marca sua presença com o diáfano, com a matéria fluida, criando um nexo inesperado entre Francisco Goya, Oswaldo Goeldi, e ele próprio. Unidos 
também pelas letras, os artistas travam relações interessantes com o texto, a palavra, e a literatura. No caso de Goya, a palavra aparece inscrita na imagem, em mensagens que por vezes soam cifradas, enquanto Goeldi tem a palavra ao lado, no âmbito da ilustração literária, e Nuno Ramos na produção musical, literária, e mesmo nas artes plásticas, seus textos por vezes aparecem materializados em resinas, parafinas e relevos. Outra marca de semelhança é a aproximação da gravura, enquanto trabalha Goya nos metais e Goeldi nas madeiras, Nuno se aproxima conceitualmente dos princípios da técnica, testando reações e interações entre os materiais, como a forma como grava a fumaça e a fuligem nas imagens, em uma analogia à monotipia.

\section{Populacho, da série Los desastres de la guerra: a biografia cultural de y Lucientes}

A ideia de biografia cultural das coisas é cara à análise de outra dimensão do objeto, no caso, as obras da série y Lucientes de Nuno Ramos, que pode apresentar traços de decolonialidade, que é a sua história, trajetória e forma de circulação, levando em conta os meios por onde passa.

No campo da História da Arte, a biografia tradicionalmente teve como personagem principal os artistas. Quando os objetos artísticos ganham o protagonismo da biografia, algumas questões fundamentais do gênero são transformadas. A construção dinâmica da personalidade, por exemplo, é dada pela constante ressignificação da obra em cada ambiente em que é inserida. Mudanças em tempo, espaço, cultura, provocam esta instabilidade na identidade do objeto. Os objetos ganham vida, e é levado em conta seu poder de atuação nas relações sociais, através de sua agência, e então ganham biografia, na qual é privilegiado o trajeto, o itinerário da obra, e as transformações culturais decorrentes de significado atribuído. Se a biografia do artista teve, em parte, a função de esclarecer a obra, a biografia do objeto artístico, por sua vez, ilumina questões sobre as contribuições destes objetos para a história da arte e o cenário artístico local, sobre a atuação das instituições, sobre as sociedades em que mergulham e por fim, revela a plasticidade contextual da obra. Essa é a subjetividade do eu biografado, o objeto artístico.

A discussão acerca da biografia cultural das coisas remonta a formulações de Igor Kopytoff (2008), primeiramente publicadas em 1986 no artigo A biografia cultural das coisas: mercantilização como processo, em que o 
autor encontra uma via de considerar a história acumulada pelos objetos, que os diferencia de seus similares, mediada por processos de mercantilização transformadores, que alteram o estado do objeto entre vulgarizações e singularizações, através de trocas econômicas em trânsitos locais e globais, como ilustrado pelo exemplo abaixo.

O que dizer de um Renoir que acabe numa coleção particular e inacessível? Ou de um outro Renoir esquecido no porão de um museu? Como deveríamos nos sentir sobre um terceiro Renoir que saia da França para os Estados Unidos? Ou para a Nigéria? As reações culturais a tais detalhes biográficos revelam um emaranhado de julgamentos estéticos, históricos e mesmo políticos, e de convicções e valores que moldam as nossas atitudes quanto a objetos designados como "arte". (KOPYTOFF, 2008: p. 93)

Trazendo essa reflexão para o objeto do presente artigo, buscamos delinear dois episódios da chamada biografia cultural de y Lucientes, que foi apresentada na seção Nova, para obras criadas a partir de 2015, da notória feira internacional Art Basel, em Miami em 2017, e uma parte dessa série que aparece na exposição O que não é floresta, é prisão política, com início em 2019 e encerramento em 2020, em um espaço diametralmente oposto, na Galeria Reocupa, em São Paulo. Trata-se de um projeto de exposições de arte contemporânea desenvolvido na Ocupação 9 de Julho, cujo prédio pertencente ao INSS, é ocupado desde 1997, e é organizado pelo Movimento Sem Teto do Centro (MSTC) desde 2016. O edifício foi construído em estilo art déco na década de 1940 e havia sido esvaziado cerca trinta anos depois, fruto da mudança da centralidade urbana em direção à Avenida Paulista, e depois à Faria Lima (SANCHES; STEVENS; PIOTTI, 2019).

O movimento social pela moradia e a ocupação de prédios que não cumprem a função social da propriedade demarcam a luta pelo direito à cidade. A exposição denota uma maneira singular de engajamento político da arte contemporânea, diretamente com a causa, visto que a Ocupação é referencial no âmbito da organização de sua dinâmica interna e forma uma rede colaborativa que se expande para a Galeria, que tem sua gestão compartilhada entre artistas, curadores, arquitetos, gestores culturais e militantes do MSTC, atuando em parceria com os moradores. O comentário de Fábio Cypriano (2019: n.p.) sobre sua visita no local enfatiza o pioneirismo dessa iniciativa que pavimenta um novo caminho de pensamento sobre as relações entre arte, política e dinheiro.

Mas o essencial realmente é perceber como essa exposição dá início a uma nova chave de posicionamento artístico, estimulado através de uma rede de colaboração fora do circuito institucional tradicional e longe do circuito comercial convencional de galerias 
e feiras, porque lá há obras vendidas para manutenção do espaço e auxílio à ocupação, apontando que é possivel se repensar a relação de vendas na arte.

É nesse contexto que é exposta a obra de Nuno Ramos (Fig. 3) que revela em parte a gravura Populacho, de número 28 da série de Goya (Fig. 2). José Manuel Matilla (MENA MARQUÉS, 2008: 314) comenta as acepções da palavra populacho segundo o dicionário da Real Academia Espanhola, que oferece dois sentidos, primeiro, parte ínfima do povo, e segundo, multidão em revolta. A imagem gravada pelo mestre espanhol dá vida a múltiplos entendimentos e revela uma das facetas mais complexas da insurreição espanhola frente a ocupação napoleônica, que é a revolta popular desmedida, a violência como forma de levante frente às privações de direitos, de meios de subsistência, que rendeu o ataque ufanista generalizado aos franceses, aos ilustrados considerados afrancesados, aos defensores do governo de José I, irmão de Napoleão, e qualquer um sobre o qual pairasse qualquer dúvida sobre seu amor à pátria.

Figura 2

Francisco Goya.

Populacho (28 da série Os Desastres da Guerra), 1863. Água-forte, ponta seca, buril, (1a ed.), $24,9 \times 34,2 \mathrm{~cm}$, Museu do Prado, Madrid. Disponível em: <https:// www.goyaenelprado.es/obras/ ficha/goya/populacho- $1 />$ acesso em $31 / 01 / 2020$

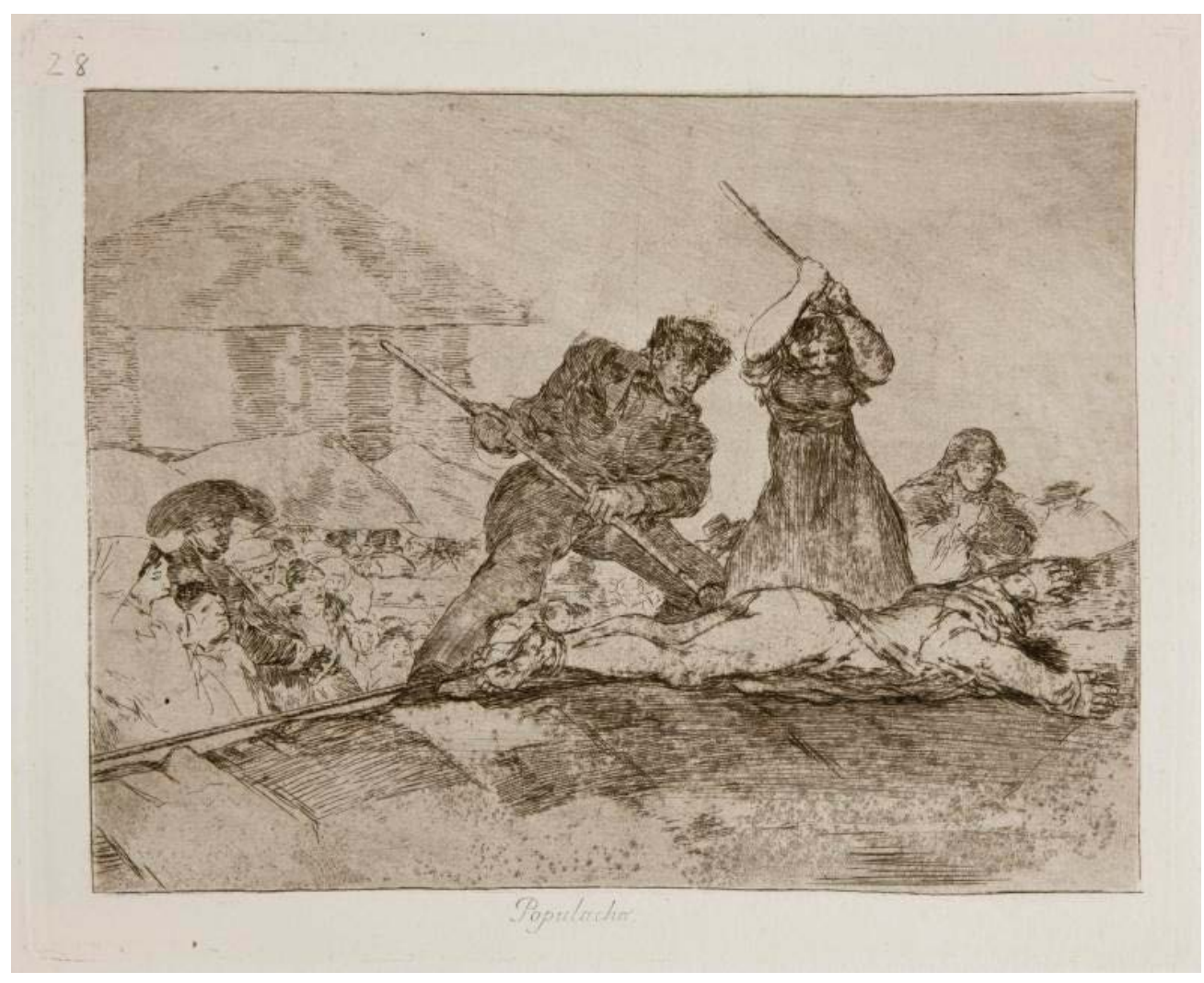

A visão do artista sobre o momento histórico e político que vive é de desolação, colaborada pelos conflitos armados, pela miséria generalizada, pela 
corrupção e promiscuidade dos poderes instituídos, laico e religioso. Não se identifica com o ambiente de Corte compatível com as nomeações a Pintor de Câmara e Pintor do Rei, pois mantém gostos populares pela boemia e pelas touradas, mas tampouco é familiarizado com os sentimentos populares de religiosidade e ufanismo. Tampouco se reconhece nos ilustrados tocados de dandismo, resultando em uma forma de inadequação, que configura uma mística do personagem de Goya como um ser deslocado, sentimento que também ecoa na fala de Nuno Ramos acima citada sobre o momento que originou a série.

A imagem recriada pelo artista contemporâneo altera ligeiramente a composição original. Tal como em Fumaça para Goeldi, é posicionada na região superior do campo visual, abrindo um largo espaço abaixo a ser atacado pela fumaça, que atinge principalmente o grupo de pessoas à esquerda, que encarnavam um dos aspectos pejorativos da palavra que dá título à

Figura 3 Nuno Ramos. Populacho (da série $y$ Lucientes), 2017. Desenho de fumaça sobre reprodução em papel, $40 \times 29$ cm. Galeria Reocupa, São Paulo. Fonte: Fotografia da Galeria Reocupa, 2019

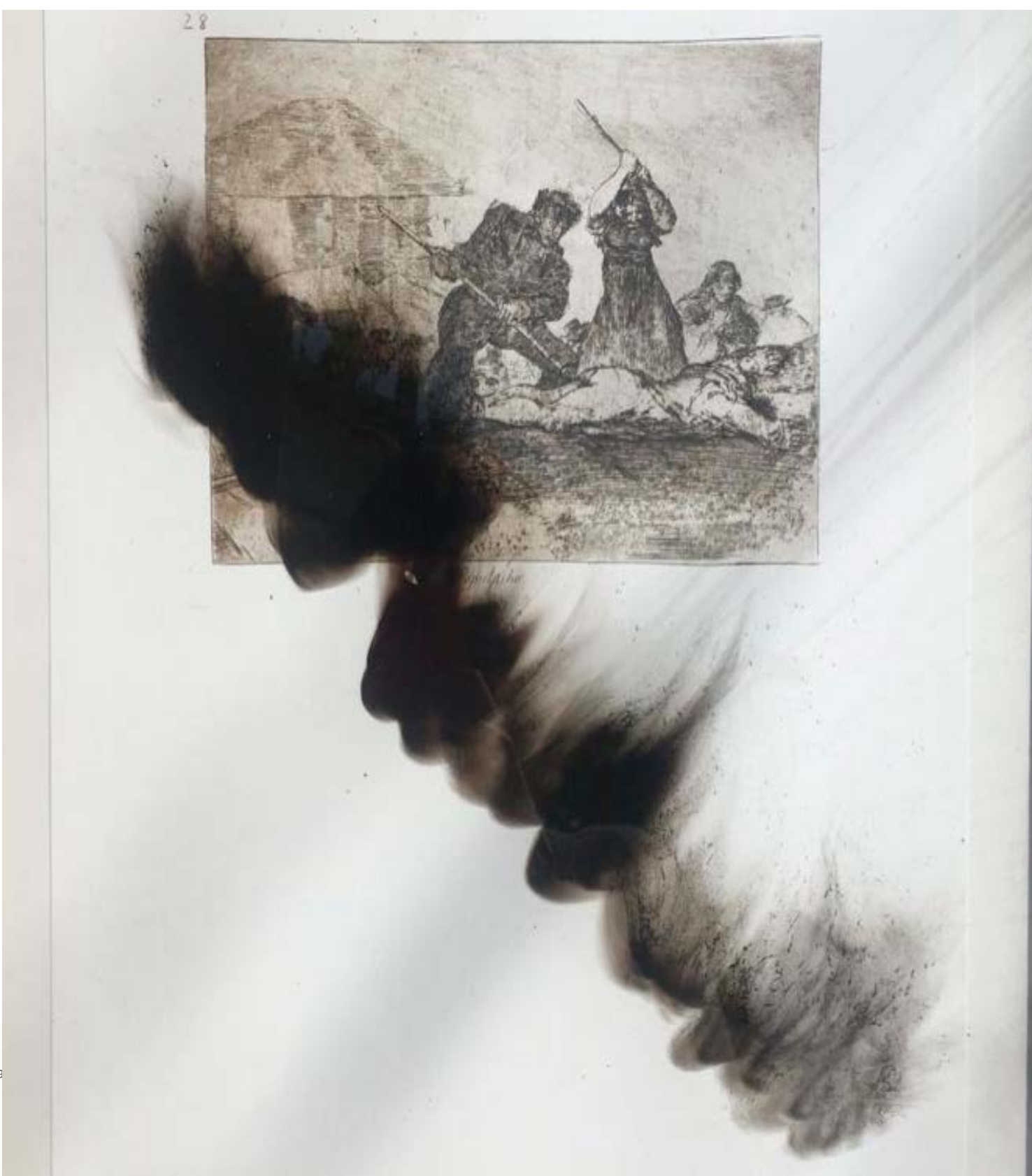


gravura, de uma multidão indiferente à brutalidade que se acoberta no anonimato do coletivo, restando o par principal que usa de sua força hercúlea como forma de libertação do mal opressor. O espaço em que a obra se localiza corrobora com o sentido de uma rebelião contra injustiças.

Deste modo, é possível notar como a obra é contextualizada em cada um dos ambientes pelo qual transita, demonstrando a ideia de Kopytoff (2008: 93): "o que é significativo sobre a adoção de objetos estrangeiros e ideias estrangeiras - não é a sua adoção, mas sim a maneira pela qual eles são culturalmente redefinidos e colocados em uso." Enquanto objeto cultural, os Desastres de Goya foram culturalmente redefinidos e colocados em uso na apropriação promovida pela obra de Nuno Ramos, e o processo de transformação segue conforme as imagens modificadas circulam.

O contraste entre os ambientes que a obra Populacho, da série y Lucientes habitou demonstra a maleabilidade do sistema da arte contemporânea, que se abre a novos lugares, e como as imagens são afetadas por esses deslocamentos. O espaço que a feira internacional configura no sistema de arte é antagônico ao espaço que a exposição na Ocupação inventa. A Art Basel de Miami, iniciada em 2002, é a maior feira de arte contemporânea dos Estados Unidos, e teve um poder transformador sobre a cidade que se instalou. Os efeitos de enobrecimento urbano que causou no bairro de Wynwood vão de encontro com a causa representada pela Galeria Reocupa e pela exposição $O$ que não é floresta é prisão política. A globalização oferecida por uma feira internacional como a Art Basel acaba por reproduzir hierarquias e desigualdades globais e monopoliza o mercado de arte em torno de grandes centros do mercado financeiro (THOMPSON, 2011).

A indagação de lgor Kopytoff sobre o lugar da obra, um dos componentes de sua biografia cultural, como um gerador de sentido e valor através de “julgamentos estéticos, históricos e mesmo políticos, e de convicções e valores que moldam as nossas atitudes quanto a objetos designados como 'arte'”, é apropriada para tratar da obra de Nuno Ramos, que se desloca em instâncias díspares do sistema da arte contemporânea local e global, e de fato, acarreta em julgamentos.

\section{Conclusão}

É possível pensar os gestos de Nuno Ramos como análogos a alguns anseios da decolonialidade, como o resgate que opera da arte do passado 
brasileiro e global, concebendo um elo de ligação entre Goya e Goeldi, e também tem a perspectiva da circulação das obras que compõem a série y Lucientes, que desafiam a lógica do sistema de arte contemporânea, ao marcarem presença em um evento de grande circulação de capital, em Miami, e a opção por exibir uma das obras da série na Ocupação 9 de Julho, na Galeria Reocupa, apoiando esse projeto artístico e social. A participação acarreta uma ativação da imagem através da luta social promovida pelo espaço, uma forma contemporânea de insurgência e resistência contra a subtração do direito fundamental à moradia.

A circulação da imagem e do objeto artístico empreendidas na obra de Nuno Ramos retomam a questão inicial acerca das definições da arte brasileira. A conclusão de Moacir dos Anjos (2005: 69-70) se dedica mais detidamente à região Nordeste, no entanto, é possível estender o pensamento ao país de modo geral.

No início da década de 1970, Hélio Oiticica disse que o Brasil não existia, sugerindo, é provável, a dissolução de uma ideia hegemônica do país, a qual iria efetivamente ocorrer, ainda que de forma gradual e lenta, nas décadas seguintes. Talvez seja possível dizer que o Nordeste do Brasil, como espaço de limites simbólicos definidos, tampouco exista. Permanece em todo caso, como repositário de símbolos, mitos, técnicas, imagens e procedimentos e o confirmam como partícipe da diversa, complexa e impura herança cultural do mundo. E se é pouco prudente tentar estabelecer os contornos precisos de uma idéia de Nordeste no mundo contemporâneo, pode-se afirmar, com alguma segurança, que as distinções dicotômicas presentes em debates travados na primeira metade do século XX (tradição versus europeização, Regionalismo versus Modernismo) não fazem mais sentido. As produções de seus artistas não buscam afirmar a identidade de um território com fronteiras rígidas nem tem pretensões de nacionalizar o que é falado de um lugar do país. Somadas, apenas participam, de uma posição específica, dos embates transculturais que a globalização ativa.

A conjuntura explorada no artigo demonstra a possibilidade de conciliação de diversos problemas da criação da arte brasileira. A obra apresentada está em consonância com questões pertinentes à sociedade e ao momento político atual, e é posta em circulação para apreciação livre do povo, trabalhando em prol de uma questão social relevante. Ao mesmo tempo, participa do cenário internacional da arte contemporânea, não se afasta de questões da linguagem artística, e tampouco da história da arte local e global, escapando também do retorno à busca de categorias nacionais como forma de representatividade, perigo ao qual os autores (QUIJANO, 1992: 437 apud MIGNOLO, 2007: 28) alertam, ao sinalizarem que não é pela via de rejeição completa da modernidade, que se atinge o desprendimento decolonial. A obra de Nuno Ramos mostra uma saída de larga distância desta ameaça, mobilizando imagens do passado, criando novos nexos através de sua fumaça. 


\section{Referências}

BARCINSKI, Fabiana Werneck (org.). Sobre a arte brasileira: da pré-história aos anos 1960. São Paulo: Edições Sesc São Paulo, Editora WMF Martins Fontes, 2015.

CANTON, Kátia. Nuno Ramos "conversa" com Osvaldo Goeldi em exposição. Folha de São Paulo. São Paulo, 26 set. 1996. Ilustrada. Disponível em: <https://www1.folha.uol.com.br/fsp/1996/9/26/ilustrada/10.html>. Acesso em: 20 jan. 2020.

CHIARELLI, Domingos Tadeu. Arte internacional brasileira. 2. ed. São Paulo, SP: Lemos, 2002.

COLI, Jorge. Fabricação e promoção da brasilidade: arte e questões nacionais. Perspective. Paris, n. 2, p. 17-64, 2013. Disponível em: <https:// journals.openedition.org/perspective/5541> Acesso em 20 fev. 2020.

CYPRIANO, Fábio. Quando arte é resistência. Arte!Brasileiros. São Paulo, v. 49, nov. 2019. Disponível em: <https://artebrasileiros.com.br/arte/exposicoes/quando-arte-e-resistencia/> Acesso em 20 fev. 2020.

DOS ANJOS, Moacir. Local/Global: arte em trânsito. Rio de Janeiro: Jorge Zahar, 2005.

DUFOUR, Gérard. Goya durante la Guerra de la Independencia. Madri: Ediciones Cátedra, 2008.

GOBBI, Nelson. Nuno Ramos enfrenta com cores os tempos cinzentos da política. O Globo. Rio de Janeiro, 7 set. 2017. Cultura. Disponível em: < $\underline{\text { ht- }}$ tps://oglobo.globo.com/cultura/nuno-ramos-enfrenta-com-cores-os-tempos-cinzentos-da-politica-1-21794865> Acesso em 20 fev. 2020.

HELMAN, Edith. Trasmundo de Goya. Madri: Alianza, 1986.

KOPYTOFF, Igor. A biografia cultural das coisas: a mercantilização como processo. In: APPADURAI, Arjun (org.). A vida social das coisas: as mercadorias sob uma perspectiva cultural. Niterói: EdUFF, 2008. p. 89-121.

LEITE, José Roberto Teixeira. A gravura brasileira contemporânea. Rio de Janeiro, RJ: Expressão e Cultura, 1966.

MENA MARQUÉS, Manuela B. (ed.). Goya en tiempos de guerra. Madrid: Museo del Prado, 2008.

MIGNOLO, Walter D. Desobediencia Epistémica: retórica de la Modernidad, lógica de la colonialidad y gramática de la descolonialidad. Buenos Aires: Del Signo 2010. (Colección Razón Política)

. El Pensamiento Decolonial: Desprendimiento y Apertura. Un ma- 
nifiesto. In: CASTRO-GÓMEZ, Santiago; GROSFOGUEL, Ramón (ed.). EI giro decolonial: reflexiones para una diversidad epistémica más allá del capitalismo global. Bogotá: Siglo del Hombre Editores, Universidad Central, Instituto de Estudios Sociales Contemporáneos y Pontificia Universidad Javeriana, Instituto Pensar, 2007. p. 25-46.

OSTROWER, Fayga. Goya: artista revolucionário e humanista. São Paulo: Editora Imaginário, 1997.

RAMOS, Nuno. Ensaio Geral: projetos, roteiros, ensaios, memória. São Paulo: Globo, 2007.

RAMOS, Nuno. Nuno Ramos. Rio de Janeiro, RJ; São Paulo, SP: Centro de Arte Hélio Oiticica: MAM, 2000.

RESTREPO, Eduardo; ROJAS, Axel. Inflexión decolonial: fuentes, conceptos y cuestionamientos. Popayán: Instituto de Estudios Sociales y Culturales Pensar, Maestría en Estudios Culturales, Universidad Javeriana, Editorial Universidad del Cauca, 2010. (Colección Políticas de la alteridad)

RUFINONI, Priscila Rossinetti. Oswaldo Goeldi: iluminação, ilustração. São Paulo: Cosac Naify, 2006.

SANCHES, Débora; STEVENS, Jeroen; PIOTTO, Marcele. Ocupações e Urbanismo Insurgentes: área central de São Paulo. In: ROZESTRATEN, Artur S. et al. Colóquio Internacional ICHT - Imaginário: Construir e Habitar a Terra. Deformações, Deslocamentos e Devaneios, 3, 2019, São Paulo. Atas... São Paulo: LPG FAUUSP, 2019. p. 426-441.

SARDENBERG, Ricardo (org.). Nuno Ramos. Rio de Janeiro: Editora Cobogó, 2010.

SCHWARCZ, Roberto. Nacional por subtração. In: Que horas são? Ensaios São Paulo: Companhia das letras, 1987. p. 29-48.

SCOVINO, Felipe; MARTINS, Sérgio Bruno (ed.). Moacir dos Anjos and Agnaldo Farias in Conversation with Felipe Scovino. Third Text. Londres, vol. 26, n. 1, 2012, p. 5-15. Disponível em: <https://doi.org/10.1080/095288 22.2012.647656> Acesso em 20 jan. 2020.

TASSINARI, Alberto; MAMMÍ, Lorenzo; NAVES, Rodrigo. Nuno Ramos. São Paulo: Editora Ática, 1997.

TAVORA, Maria Luisa. A crítica e a gravura artística - anos 50-60: entendimentos da experiência informal. Arte \& Ensaios. Revista do Programa de Pós-Graduação em Artes Visuais da Escola de Belas Artes da UFRJ. Rio de Janeiro, n. 27, p. 121-131, 2013.

THOMPSON, Emily Rose. The growth and evolution of Art Basel Miami 
Beach. 2011. 90f Dissertação (Mestrado em Artes) - Faculty of the College of Arts and Sciences, American University, Washington, 2011.

TODOROV, Tzvetan. Goya à sombra das luzes. São Paulo: Companhia das Letras, 2014.

TOMLINSON, Janis A. Goya: en el crepúsculo del siglo de las luces. Madrid: Cátedra, 1993.

Recebido em 24 de março de 2020 e aceito em 29 de abril de 2020.

Este é um artigo publicado em acesso aberto sob uma licença Creative Commons (cc)) 